\title{
Use of the Newly Synthesized Aqueous Polyurethane Acrylate Binders for Printing Cotton and Polyester Fabrics
}

\author{
Mohamed M. El-Molla*, Hanan S. El-Sayad, Madiha A. El-Kashouti, Rasha S. El-Khawaga \\ Textile Research Division, National Research Centre, Cairo, Egypt \\ Email: *melmolla@yahoo.com
}

Received September 21, 2011; revised November 16, 2011; accepted December 27, 2011

\begin{abstract}
The use of the four new synthesized polyurethane acrylate binders in the pigment print paste for screen printing cotton and polyester fabrics and pigment fixation through the polymerization process of the binder by using the thermofixation technique as well as the UV curing technique was studied. The effect of changing time and temperature of thermofixation, and the time of UV curing on the color strength, and prints fastness properties were also studied. The results showed that, the newly synthesized polyurethane acrylate binders could be successfully used for pigment fixation on cotton and polyester using the two fixation techniques and in general their prints possessed better color strength values as compared to those obtained upon using the selected commercial binders.
\end{abstract}

Keywords: Synthesized; Aqueous Polyurethane; Acrylate Binders; Screen Printing; Cotton; Polyester; Curing

\section{Introduction}

Pigment printing is not only the oldest but also the easiest printing method as far as simplicity of application is concerned [1-5]. More than $80 \%$ of the printed goods are based on pigment printing due to its obvious advantages, such as versatility, ease of near final print at the printing stage itself, etc. Pigment printing makes use of kerosene or mineral turpentine which is involved in making emulsion thickeners. In this system, the kerosene in the emulsion gets evaporated to the atmosphere at the time of curing of the pigment printed fabric [6]. It is almost impossible to reclaim this kerosene. In spite of the superior thickening properties of kerosene water emulsion which also contribute towards a soft hand of the print, good fastness properties, ease of application methods, and economy. Several other factors have compelled the search for a replacement for kerosene; some of these are [7]:

1) The ongoing oil crisis, both in terms of cost and availability makes it imperative to minimize kerosene use.

2) When printed fabrics are dried and cured in ovens, the surrounding atmosphere in the oven must contain enough excess of air volume in relation to the volatile hydrocarbon volume to ensure that the mixture is below the explosion point. A number of fatal accidents caused by explosions in curing ovens proved that this system is

\footnotetext{
*Corresponding author.
}

highly risky.

3) The emission of high percentage of hydrocarbons through the curing exhausts is considered to be posing a very serious problem.

The use of synthetic thickening agents and new developments in printing auxiliaries have also contributed to the increasing importance of pigment printing, since here, too, environmental aspects such as minimization of formaldehyde emissions and carbon dioxide content must be taken into account. At the same time, novel binder systems allow a much softer handle to be attained [8]. Formaldehyde emissions and clogging on the screens during the actual printing process must also be taken into account [9-11]. These disadvantages are related to the binders used.

$\mathrm{UV}$, as well as radiation curing technologies are used in many industrial application-as well as in the textile area, because of low energy consumption, short start-up period, fast and reliable curing, low environmental pollution, curing at room temperature, space saving ,etc.

The aim of this work was to investigate the use of the synthesized aqueous polyurethane acrylate binders, having zero volatile organic emissions based on glycerol Ethoxylate-Co-Propoxylate triol in pigment printing of cotton and polyester fabrics by the silk screen technique, and pigment fixation through the polymerization process of the binder by using the thermofixation technique, as well as the newly adopted UV technique. 


\section{Experimental}

\subsection{Materials}

\subsubsection{Fabric}

$100 \%$ Polyester knitted fabric of $150 \mathrm{~g} / \mathrm{m}^{2}$, supplied by a private sector company.

$100 \%$ scoured bleached cotton fabric of $140 \mathrm{~g} / \mathrm{m}^{2}$, supplied by a private sector company.

\subsubsection{Pigment}

Bercolin Red B3E.supplied by Berssa, Turkey.

\subsubsection{Binder}

- The synthesized aqueous polyurethane acrylate binders $(1$ - 4) based on glycerol Ethoxylate-Co-Propoxylate triol.

- Commercial binder for thermal curing namely Bercolin metal CM supplied by Berssa, Turkey.

- Commercial binder for UV curing namely Ebecryl 2001 supplied by UCB, Belgium.

\subsubsection{Printing Auxiliaries}

1) Thermal initiator

Ammonium persulfate $\left(\mathrm{NH}_{4}\right)_{2} \mathrm{~S}_{2} \mathrm{O}_{8}$ Merck, Germany. 2) Photo initiator

Esacure DP250 supplied by lamberti spa Italy.

\subsubsection{Thickening Agents}

Bercolin CPK, supplied by Berssa, Turkey.

\subsection{Methods}

\subsubsection{Preparation of Binder}

Four derivatives of polyurethane acrylate binders having different contents of vinyl groups were prepared as illustrated in paper [12].

\subsubsection{Printing}

\section{1) Preparation of Printing Pastes}

The pigment printing pastes were prepared according to the following recipe:

\begin{tabular}{cc}
\hline Pigment & $50 \mathrm{~g}$ \\
Binder* & $\mathrm{X}$ \\
Thickener & $40 \mathrm{~g}$ \\
Initiator** & $10 \mathrm{~g}$ \\
Distilled water & $\mathrm{Y}$ \\
& $1000 \mathrm{~g}$ \\
\hline
\end{tabular}

*The Binder concentration used was either $(2.5 \%, 5 \%$ or $7.5 \%)$ of the 1 ) Synthesized polyurethane acrylate binders; 2) Bercolin metal CM (Commercial binder for thermal curing); 3) Ebecryl 2001binder (commercial binder for UV curing). **The initiator used was either thermal initiator which is ammonium persulfate or photoinitiator which is Esacure DP250.

\section{2) Printing technique}

Two printing pastes were prepared, one type for thermal and another type for UV-curing. The conventional pigment paste for thermal curing contained the thermal initiator ammonium persulphate and the UV pigment paste contained the UV curing photo initiator esacure DP250, in addition to the other ingredients. All the prepared and well homogenized printing pastes were applied to the fabrics using a flat silk screen.

\section{3) Fixation of prints}

The printed samples with the thermal type printing pastes were thermofixed at different fixation temperatures $\left(140^{\circ} \mathrm{C}, 160^{\circ} \mathrm{C}\right.$ or $180^{\circ} \mathrm{C}$ ) for periods of (3 or 5 min.), and the printed samples with the UV type printing pastes were UV cured using UV rays at wave length 254 $\mathrm{nm}$, for (5\%, 10\%, and $15 \mathrm{~min}$.)

\subsection{Measurements and Analysis}

\subsubsection{Color Strength Measurements}

The color strength results of the printed samples were evaluated by Hunter lab UltraScan PRO and expressed as K/S [13].

\subsubsection{Fastness Properties}

Fastness properties to washing, rubbing and perspiration were measured according to a standard method [14].

\section{Results and Discussion}

The difference between dyeing processes and pigmentation is that pigment colored textiles require a curing procedure. Since pigments do not have an affinity to textiles. Pigment fixation on textiles relies on binders that require a curing process to hold the pigments on a textile. Conventional curing is a thermal process where pigment colored textiles must be dried and then cured with heat to convert the soft organic base (monomer and/or oligomer) to a tough polymer [15].

UV curing is an alternative to the thermal process. UV curing resin formulations content oligomers, monomers, and photo initiators. These components can be polymerized (hardened) by the free radical mechanism [16-19] shown in Figure 1 using of a photo initiator triggers a nearly instantaneous curing reaction upon exposure to UV light. Thus UV curing produces a completely polymerized network in seconds and is faster than thermal curing [20]. UV curing for pigment printing has been studied [21-23]. Problems associated with the process include low crock fastness, stiff fabric hand and low curing efficiency of the resin when pigments are involved.

The work in this paper was carried out with the following objectives in mind:

Use and evaluation of the synthesized polyurethane acrylate binders $(1-4)$ based on glycerol Ethoxylate-Co- 


$$
\begin{aligned}
& \text { R - R } \\
& \text { Initiator } \\
& \underset{\text { Radical generation }}{\stackrel{\mathrm{UV} \text { Light }}{\longrightarrow}} \mathrm{R}-\mathrm{R} \\
& \mathrm{R}+\mathrm{CH}_{2}=\mathrm{C}_{\mathrm{H}}^{\prime} \underset{\text { Initiator }}{\mathrm{R}} \longrightarrow \mathrm{R}-\mathrm{CH}_{2}-\mathrm{C}_{\mathrm{H}}^{\mathrm{R}} \\
& \mathrm{R}-\mathrm{CH}_{2}-\mathrm{C}_{\nu_{\mathrm{H}}}^{\mathrm{R}}+\mathrm{CH}_{2}=\mathrm{C}_{\mathrm{H}}^{\mathrm{R}} \longrightarrow \mathrm{R}-\mathrm{CH}_{2}-\left.\right|_{\mathrm{H}} ^{\mathrm{C}}-\left.\mathrm{CH}_{\mathrm{H}}^{\mathrm{R}}\right|_{\mathrm{C}} ^{\mathrm{R}} \\
& \mathrm{R}-\mathrm{CH}^{2}-\mathrm{C}_{\mathrm{H}}^{\mathrm{R}}+\mathrm{R} \\
& \longrightarrow \mathrm{R}-\mathrm{CH}_{2}-\mathrm{C}_{\mathrm{H}}^{\mathrm{C}}-\mathrm{R}
\end{aligned}
$$

Figure 1. Mechanism of radical polymerization.

Propoxalate triol [12], as binders in the pigment printing pastes to be used for pigmenting cotton and polyester fabrics by the silk screen techniques, and subsequent fixation of the pigments by either the thermal fixation curing or UV fixation curing techniques. The results were always compared with those obtained when a commercial binder was used in every case under similar conditions. Finally comparison between the results obtained by the two techniques.

\subsection{Thermal Cured Pigment Prints}

\subsubsection{Cotton}

In the first stage of the investigation, the prepared pigment pastes, containing 5\% Bercolin Red B3E, and different concentrations $(2.5 \%, 5.0 \%$, and $7.5 \%)$ of the synthesized polyurethane acrylate binders $(1-4)$, as well as the commercial binder (thermal type), were printed on cotton fabrics by the flat screen technique, dried and then thermally polymerized with hot air at different fixation temperatures $\left(140^{\circ} \mathrm{C}, 160^{\circ} \mathrm{C}\right.$ and $\left.180^{\circ} \mathrm{C}\right)$ for 3 and $5 \mathrm{~min}$. intervals respectively. The color strength results of the pigment printed cotton fabrics are represented by Figures 2 and 3.

The collective diagrams show the effect of inclusion of the aforementioned binders on the color strength of the printed cotton fabrics thermally cured under the above conditions. It is clear from the results, that both the concentration and type of polyurethane acrylate binders (1 4) have some effects on the color strength value of the produced screen printed cotton prints. It can be seen that upon using binder concentration of $2.5 \%$ and $5 \%$ in the printing paste, they produce comparable color strength results. Further increase in the binder concentration up to $7.5 \%$ produced no significant color enhancement and therefore it is not recommended. Binder 1 produced cotton prints with lower color strength values, in most cases, as compared to binders 2, 3 and 4 which gave higher

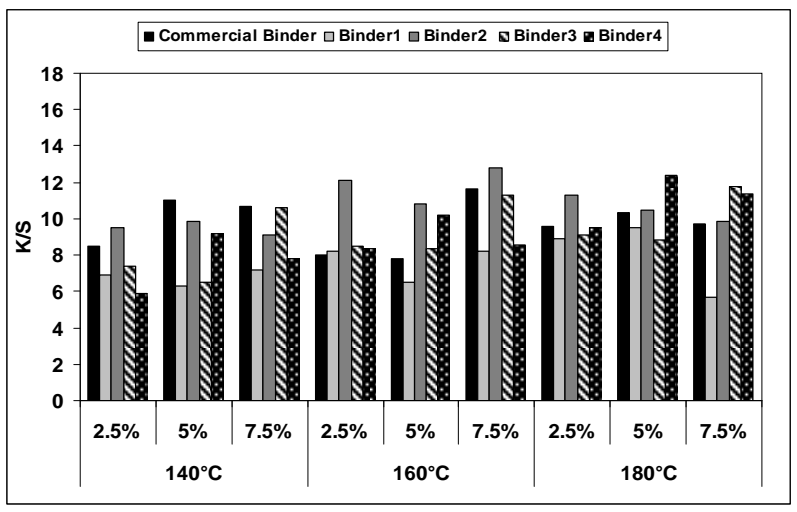

Figure 2. Effect of inclusion of different concentrations of binders $(1-4)$ as well as Bercolin Red B3E in the print paste formulation on the color strength of screen printed, thermally*cured cotton fabrics for 3 minutes. *Curing temperatures $140^{\circ} \mathrm{C}, 160^{\circ} \mathrm{C}$ and $180^{\circ} \mathrm{C}$.

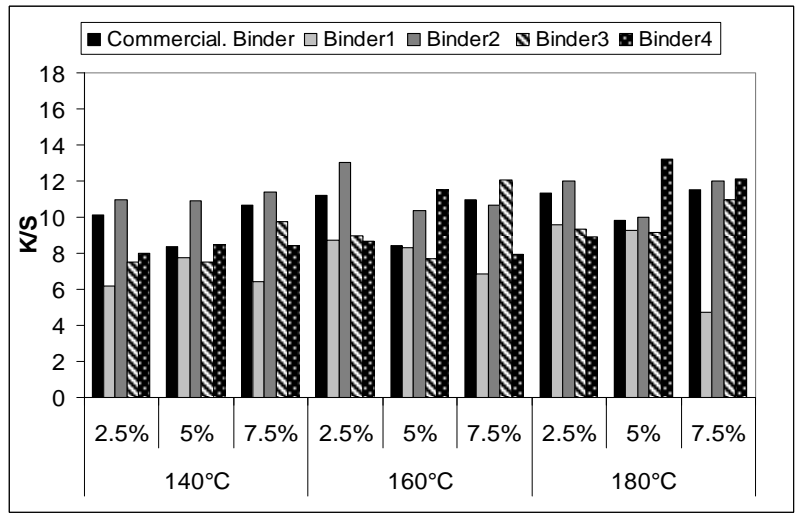

Figure 3. Effect of inclusion of different concentrations of binders $(1$ - 4) as well as Bercolin Red B3E in the print paste formulation on the color strength of screen printed, thermally*cured cotton fabrics for 5 minutes. *Curing temperatures $140^{\circ} \mathrm{C}, 160^{\circ} \mathrm{C}$ and $180^{\circ} \mathrm{C}$.

color strength results which are comparable to that obtained by the commercial binder (Bercolin metal CM), and in same cases, higher K/S values are produced under the same conditions.

The effect of increasing the thermal fixation time from 3 to 5 minutes on the color strength results of the prints is represented by Figure 3. It is clear that fixation time of 3 min. could be considered as adequate under such conditions, and no need to prolong the time of fixation any further. The effect of increasing the thermal fixation temperature from $140^{\circ} \mathrm{C}$ to $160^{\circ} \mathrm{C}$ and further to $180^{\circ} \mathrm{C}$ is slight Figures $\mathbf{2}$ and $\mathbf{3}$ and therefore it is also not recommended to use higher fixation temperatures over $160^{\circ} \mathrm{C}$ in this case. Optimum conditions of thermal fixation could be considered as $160^{\circ} \mathrm{C}$ for $3 \mathrm{~min}$.

\subsubsection{Polyester}

Figures 4 and 5 represent the effect of inclusion of different 


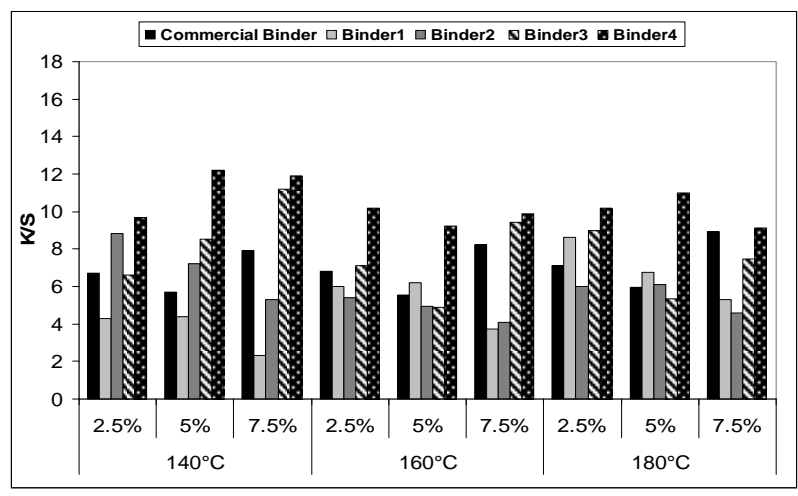

Figure 4. Effect of inclusion of different concentrations of binders $(1-4)$ as well as Bercolin Red B3E in the print paste formulation on the color strength of screen printed, thermally*cured polyester fabrics for 3 minutes. *Curing temperatures $140^{\circ} \mathrm{C}, 160^{\circ} \mathrm{C}$ and $180^{\circ} \mathrm{C}$.

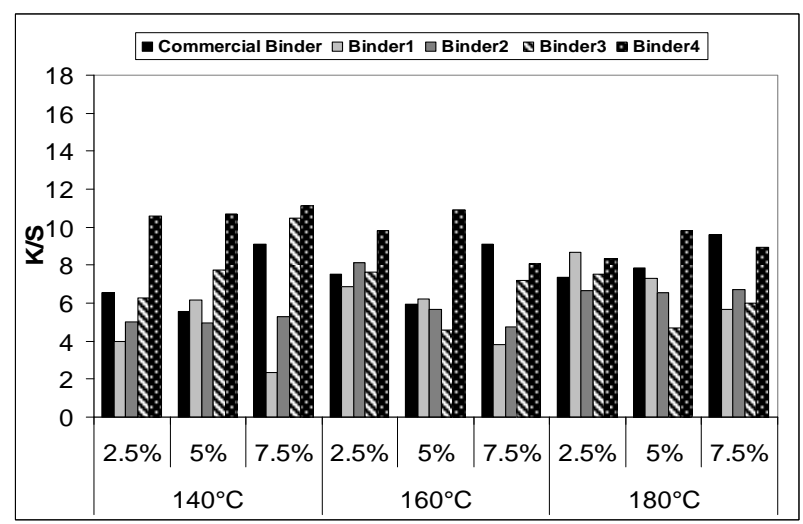

Figure 5. Effect of inclusion of different concentrations of binders $(1-4)$ as well as Bercolin Red B3E in the print paste formulation on the color strength of screen printed, thermally*cured polyester fabrics for 5 minutes. *Curing temperatures $140^{\circ} \mathrm{C}, 160^{\circ} \mathrm{C}$ and $180^{\circ} \mathrm{C}$.

concentrations of polyurethane acrylate binders (1 - 4) as well as Bercolin Red B3E in the print paste formulation on the color strength of screen printed, thermally cured polyester fabrics for 3 and 5 minutes, as compared to that of commercial binder, respectively.

It is noticed that, lower binder concentration ranging between $2.5 \%$ - 5\% (binders 1 - 4) are required in order to obtain prints with higher color strength values, further increase in the binder concentration up to $7.5 \%$ results, in some cases, in decreasing the color strength of the polyester prints. The reverse is noticed with the commercial binder (Bercolin metal CM) with which higher concentrations of $7.5 \%$ are needed to produce polyester prints with higher color strength values which has an effect on the economical aspects of the process. The above situation applied for the fixation temperatures studied $\left(140^{\circ} \mathrm{C}\right.$ $-160^{\circ} \mathrm{C}$ and $180^{\circ} \mathrm{C}$ ) and for both fixation times 3 and 5 $\min$.
Generally speaking, binder 4 seems to have produced prints with highest color strength values as compared to the results obtained by the commercial binder and binders $(1-3)$ in most cases and this could be attributed to the possibility of the replacement of higher percentage of the hydroxyl groups in the glycerol Ethoxylate-Co-propoxylate triol by vinyl groups during the process of binder synthesis, and subsequently, the increase of the amount of unsaturated groups through which increased binder polymerization occurs resulting in better pigment fixation. Fixation temperature of around $160^{\circ} \mathrm{C}$ could be recommended in this case, as the increase in fixation temperature up to $180^{\circ} \mathrm{C}$ results only in a slight increase in the color strength values of the prints. A time of fixation of $3 \mathrm{~min}$. could also be considered as optimum in this case, as further increase in fixation time is not beneficiary.

\subsection{UV. Cured Pigment Prints}

Printing with pigment dispersed in radiation curable liquid compositions and curing with ultraviolet eliminates the drying step and greatly reduces the energy required for curing. High curing speeds, high cross-linking densities and the absence of organic solvents have made UV curing a well established technology for all kinds of coating and ink applications. Although this technique is quite successful in printing on non-textile substrates, the introduction to the printing process of the non-uniform, hairy, porous fabric, which will be washed many times over its useful life and which must remain soft and flexible after printing, brings with it a number of new problems, these problems were discussed else were [24-26].

Today numerous UV-curable monomers and oligomers like polyether, polyester, epoxy, polyacrylate and urethane acrylates are available on the market. By the choice of raw materials namely oligomers as binders and accompanying monomers, and photo initiators the film properties such as hardness, flexibility, resistance and adhesion can be controlled in a very flexible way [2730].

However, in same UV-curable inks, acceptable rheology can hardly ever be achieved without the use of pigment dispersing additives. Therefore additive suppliers offer tailor-made solutions, often solvent-free and crosslinkable.

\subsubsection{Role of Photo Initiator}

Acrylic monomers do not absorb UV-light in a very efficient way and will not initiate radical plymerization fast enough. As such, a photopolymerisable film forming formulation essentially consists of a polymerisable vehicle (oligomer) and a light sensitive compound that is able to convert the absorbed light energy into a more useful 
form capable of causing the binder to polymerise into a hard solid mass.

Such a light sensitive compound is known as photoinitiator/sensitizer. Thus a photoinitiator is added which produces initiator free radicals directly by the fragmentation of the photo-excited state, these free radicals are capable of initiating the polymerization reaction.

Photoinitiator is of paramount importance in radiation curable systems. A photoinitiator is selective in terms of light of specific wavelengths. During formulation, the absorbency characteristics of the photoinitiator are matched to the radiation characteristics of the lamp output. Indeed, the choice of photoinitiator is of prime impotance in the light induced polymerization since it directly governs the cure rate [31].

\subsubsection{Cotton}

As before, the prepared pigment pastes containing 5\% Bercolin Red B3E pigment, and different concentrations (2.5, 5 and $7.5 \%)$ of the prepared polyurethane acrylate binders $(1-4)$, as well as the selected suitable commercial binder Ebecryl 2001 and the photoinitiator Esacure DP250 were printed on cotton fabrics by the flat screen technique, dried and then subjected to UV curing for different intervals of time 5, 10 and 15 minutes. The results are expressed in Figure 6 binders (1 - 4) contain some unsaturated groups, which under the effect of UV rays can undergo a polymerization reaction which leads ultimately to pigment fixation on the cotton fabrics.

The results in the collective diagram 6 show that, both the concentration and the type of polyurethane acrylate binder derivatives $(1-4)$ in the printing paste are responsible for some effects on the color strength of the screen printed cotton fabrics which were subsequently UV cured by the mercury lamp source, under atmospheric condi-

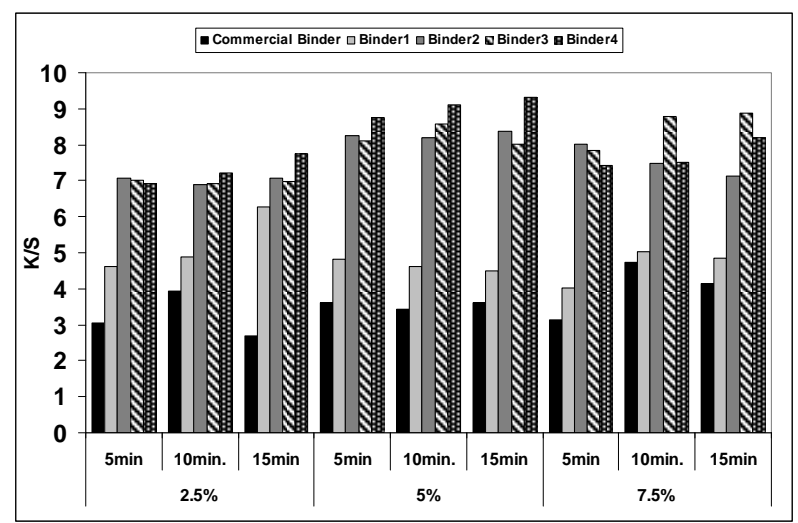

Figure 6. Effect of inclusion of different concentrations of polyurethane acrylate binders $(1$ - 4), as well as Bercolin Red B3E in the printing paste formulation on the color strength of screen printed, UV cured* cotton fabrics as compared to that of commercial binder. *UV curing time 5, 10 and 15 min. tions for different times of exposure 5, 10 and 15 minutes.

As regarding to the binder concentration, it can be seen that, generally speaking, binder concentration of $5 \%$ produce cotton prints with color strength values slightly higher than that obtained by binder concentration of $2.5 \%$ under similar fixation conditions. Higher binder concentrations the pigment printing paste gave similar and sometimes lower color strength results of the prints and this is also the case with the results of the commercial binder.

With regards to the type of binder derivative used it can be noticed that, in general, the highest color strength values were obtained in case of using binders 2,3 and 4 in the UV curable printing pastes while lower values were obtained upon using the commercial binder (Ebecryl 2001) and moderate values in between, in case of using binder 1. This is true irrespective of either the binder concentration or the UV-curing time. For example, the $\mathrm{K} / \mathrm{S}$ values of screen printed cotton fabrics with printing paste containing $5 \%$ binder and UV cured for 5 min. were 3.6, 4.8, 8.2, 8.1 and 8.7 upon using the commercial binder (Ebecryl 2001), binder 1, binder 2, binder 3 and binder4 respectively. This could be attributed to the difference in structure of the binders used as well as the difference in their contents of the unsaturated groups, which are responsible for the pigment fixation occurring due to the binder polymerization process by the UV curing technique.

It is worthy to mention that, the UV curing of pigmented prints remains difficult, due to high light absorption by the pigment, which is detrimental to light absorption by the photoinitiator [32]. An efficient cure can only be obtained by achieving the best overlap between the absorption spectrum of the photoinitiator, the transmission spectrum of the pigment, and the emission spectrum of the light [33].

It is also clear from fig. 6 that increasing the UV-curing fixation time from 5 to 10 and up to $15 \mathrm{~min}$. did not result in any increase in the color strength values of the cotton prints irrespective of the type and concentration of the binders used in these experiments. A curing time of 5 min. could be recommended under such circumstances to save energy and time.

It could be concluded that the presence of $5 \%$ concentration of polyurethane acrylate binders $(1-4)$ in the polyester pigment printing paste, and UV curing for 5 min. could be considered as optimum conditions in this case.

\subsubsection{Polyester}

Different pigment pastes containing 5\% Bercolin Red B3E pigment, and different concentrations of the synthesized polyurethane acrylate binders $(1-4)$, as well as the 
commercial binder Ebecryl 2001 and the photoinitiator Esacure DP250 were printed on polyester fabrics by the flat screen technique, dried, and UV-cured for 5, 10 and 15 minutes. The results are represented by Figure 7 the same pigment fixation technique on polyester fabrics by polymerization of the binder via the present unsaturated groups when subjected to UV curing rays was expected.

The results shown in the collective Figure 7 demonstrate that, prints with comparable color strength values were produced upon inclusion of 2.5 or $5 \%$ binder concentration in the UV curable pastes, while a decrease in the color results is noticed upon increasing the binder concentration to $7.5 \%$ under the same conditions. The type of binder derivative used in this case has a very pronounced effect, and it can be seen that UV cured prints with elevated color strength values are obtained with printing pastes containing binders 3 and 4 as compared to those containing the commercial binder, binder 1 and binder 2 . This is true irrespective of the binder concentration and the time of UV curing fixation. For example, The K/S values of screen printed polyester fabrics obtained with pastes containing $2.5 \%$ binder and UV cured for 5 minutes were 3.09, 1.64, 3.82, 6.4 and 8.9 when using the commercial binder (Ebecryl 2001), binder 1, binder 2, binder 3 and binder 4 respectively.

These results may be attributed, as before, to the difference in binder structure as well as, their contents of the unsaturation groups, as binder 3 and 4 were synthesized with higher contents of these groups, which are responsible for the binder polymerization and pigment fixation upon curing.

It could be concluded that the presence of $2.5 \%$ polyurethane acrylate binder concentration in the polyester pigment printing paste, and UV curing the polyester prints for five minutes could be considered as optimum

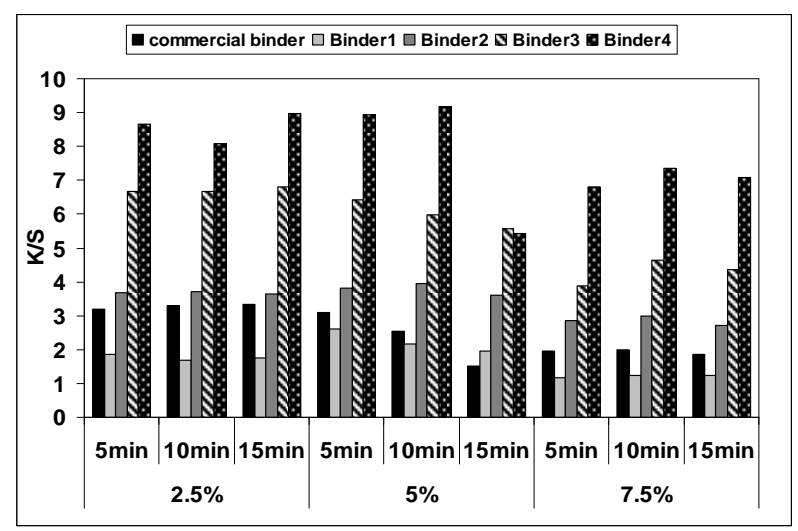

Figure 7. Effect of inclusion of different concentrations of polyurethane acrylate binders $(1-4)$, as well as Bercolin Red B3E in the printing paste formulation on the color strength of screen printed, UV cured* polyester fabrics as compared to that of commercial binder. *UV curing time 5 , 10 and $15 \mathrm{~min}$. conditions in this case.

\subsection{Comparison between the Results Obtained by Thermal and UV Curing Techniques at the Optimum Conditions}

The color strength results obtained by thermal and UV curing techniques for screen printed cotton and polyester fabrics with printing pastes containing 5\% Bercolin Red B3E pigment and 5\% binder concentration (binder 1 - 4) as compared to those obtained by the commercial binders are represented by Figure 8.

The results show that, under the selected thermal fixation conditions of $160^{\circ} \mathrm{C}$ for 3 min., and UV curing conditions of $5 \mathrm{~min}$., the thermally cured cotton and polyester prints possessed comparable, but with slightly higher color strength values when compared with the corresponding UV cured prints upon using binders 1, 2, 3 and 4 although prints obtained upon using binder 4 possessed the highest $\mathrm{K} / \mathrm{S}$ values.

It is also clear that cotton prints acquired better color strength values than polyester prints under the same conditions upon using both thermal and UV curing techniques. It can also be seen that the K/S results of the UV cured prints obtained using binders $(1-4)$ were much improved in comparison to those of the commercial binder.

It could be safely concluded that, the four synthesized aqueous polyurethane acrylate binders could be successfully employed for pigment fixation on screen printed cotton, and polyester via polymerization of the binders during the thermal and UV curing processes and in general, their prints possessed better color strength values as compared to those obtained upon using the commercial

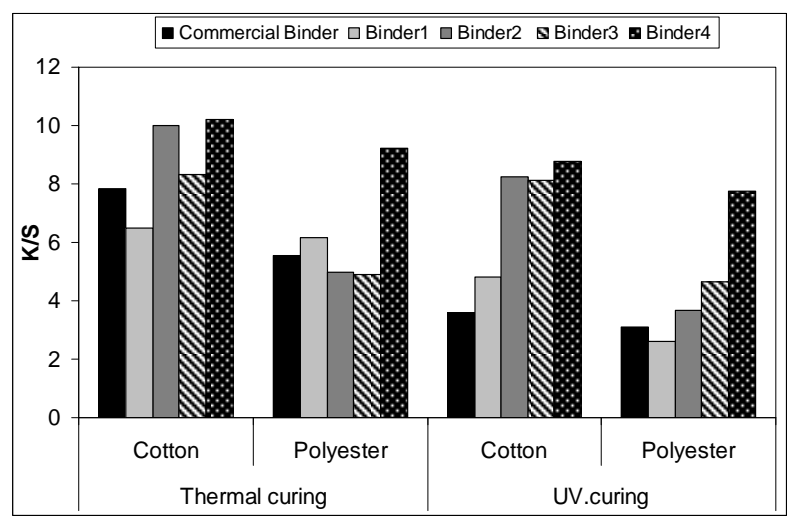

Figure 8. Comparison between the results obtained by thermal* and UV* curing techniques for screen printed cotton and polyester fabrics with printing pastes containing $5 \%$ Bercolin Red B3E pigment and 5\% binders (1 - 4) compared to those obtained by the commercial binders*. *Curing temperatures $160^{\circ} \mathrm{C}$ for $3 \mathrm{~min}$. * $\mathrm{UV}$ curing time $5 \mathrm{~min}$. *Bercolin metal CM for thermal curing and Ebecryl 2001 for UV curing. 
binders.

\subsection{Fastness Properties}

Since pigment printing either by thermal or UV curing is a surface application, the major concern is the abrasion resistance of the print on the fabric either towards washing or rubbing. In thermal baking process, the crosslinking is essential for the adhesion of the binder to the textile surface and to give the pigment print optimum fastness properties [34].

Applying high curing temperature to fix the pigment colors, as much as needed is an unfavorable printing aspect. It does not only waste energy but also runs the risk of the thermo degradation of substrates. In UV curing, these risks are minimized [35].

Tables 1 and 2 show the color strength and overall fastness properties of screen printed and thermally cured cotton and polyester fabrics with pigment printing pastes containing 5\% polyurethane acrylate binders (1 - 4), as well as 5\% Bercolin Red B3E pigment, as compared to that obtained upon using the commercial binder (Ber- colin metal CM) respectively. The results show that, both the color strength and the fastness properties of the prints depend on the type of binder used as well as the type of the selected fabric.

The rubbing fastness results were low for all cotton and polyester prints, although some improvement is noticed with binders 2, 3 and 4 as compared to those for binder1 and the commercial binder. The washing, perspiration and light fastness ranged from good to excellent for all.

Table 3 show the roughness properties of screen printed cotton and polyester fabrics, using printing pastes containing (5\% Bercolin Red B3E, 5\% of the synthesized polyurethane acrylate binders (1 - 4), as well as the commercial binder Bercolin metal CM) and thermally cured at $160^{\circ} \mathrm{C}$ for $3 \mathrm{~min}$.

The results show that the roughness for both printed cotton and polyester depends on the type of binder derivative used. The commercial binder gave similar results to those obtained by binder1, and better results than those obtained by binders 2 - 4 .

Table 1. The color strength and overall fastness properties of screen printed, and thermally* cured cotton fabrics with pigment printing pastes containing $5 \%$ polyurethane acrylate binders $(1-4)$, as well as $5 \%$ Bercolin Red B3E pigment, as compared to that upon using the commercial binder Bercolin metal CM.

\begin{tabular}{|c|c|c|c|c|c|c|c|c|c|c|c|c|c|}
\hline \multirow{3}{*}{$\begin{array}{l}\text { Binder } \\
\text { Used }\end{array}$} & \multirow{3}{*}{$\mathrm{K} / \mathrm{S}$} & \multirow{2}{*}{\multicolumn{2}{|c|}{ Rubbing }} & \multirow{2}{*}{\multicolumn{3}{|c|}{ Washing Fastness }} & \multicolumn{6}{|c|}{ Perspiration } & \multirow{3}{*}{$\begin{array}{c}\text { Light } \\
\text { Fastness }\end{array}$} \\
\hline & & & & & & & \multicolumn{3}{|c|}{ Acid } & \multicolumn{3}{|c|}{ Alkali } & \\
\hline & & Dry & Wet & Alt. & St.1 & St.2 & Alt. & St.1 & St.2 & Alt. & St.1 & St.2 & \\
\hline $\begin{array}{c}\text { Commercial } \\
\text { Binder }\end{array}$ & 7.83 & $1-2$ & $1-2$ & $4-5$ & 5 & $4-5$ & 5 & $4-5$ & 5 & $4-5$ & 4 & $4-5$ & 5 \\
\hline Binder 1 & 6.51 & $1-2$ & $1-2$ & 3 & 4 & 4 & 4 & 4 & $3-4$ & $4-5$ & 3 & 4 & 5 \\
\hline Binder 2 & 10.79 & 2 & $2-3$ & 4 & 4 & 3 & $4-5$ & $4-5$ & $4-5$ & $4-5$ & $4-5$ & 5 & $4-5$ \\
\hline Binder 3 & 8.33 & $1-2$ & $2-3$ & 4 & 4 & $4-5$ & $4-5$ & 5 & $4-5$ & 4 & $4-5$ & $4-5$ & 5 \\
\hline Binder 4 & 10.20 & $1-2$ & $2-3$ & $4-5$ & $4-5$ & 4 & 5 & $4-5$ & 5 & 5 & $4-5$ & 5 & 5 \\
\hline
\end{tabular}

Table 2. The color strength and overall fastness properties of screen printed, and thermally* cured polyester fabrics with pigment printing pastes containing $5 \%$ polyurethane acrylate binders $(1-4)$, as well as $5 \%$ Bercolin Red B3E pigment, as compared to that upon using the commercial binder Bercolin metal CM.

\begin{tabular}{|c|c|c|c|c|c|c|c|c|c|c|c|c|c|}
\hline \multirow{3}{*}{$\begin{array}{l}\text { Binder } \\
\text { Used }\end{array}$} & \multirow{3}{*}{$\mathrm{K} / \mathrm{S}$} & \multirow{2}{*}{\multicolumn{2}{|c|}{ Rubbing }} & \multirow{2}{*}{\multicolumn{3}{|c|}{ Washing Fastness }} & \multicolumn{6}{|c|}{ Perspiration } & \multirow{3}{*}{$\begin{array}{c}\text { Light } \\
\text { Fastness }\end{array}$} \\
\hline & & & & & & & \multicolumn{3}{|c|}{ Acid } & \multicolumn{3}{|c|}{ Alkali } & \\
\hline & & Dry & Wet & Alt. & St.1 & St.2 & Alt. & St.1 & St.2 & Alt. & St.1 & St.2 & \\
\hline $\begin{array}{c}\text { Commercial } \\
\text { Binder }\end{array}$ & 5.56 & 1 & $1-2$ & 4 & $4-5$ & $4-5$ & $4-5$ & 4 & 4 & $4-5$ & $4-5$ & $4-5$ & 5 \\
\hline Binder 1 & 6.51 & 1 & $1-2$ & 3 & $3-4$ & $3-4$ & 4 & $3-4$ & 3 & 4 & $3-4$ & 4 & 5 \\
\hline Binder 2 & 4.96 & $1-2$ & $2-3$ & $3-4$ & 4 & 4 & 3 & 3 & $3-4$ & 3 & 3 & $3-4$ & 5 \\
\hline Binder 3 & 4.9 & $1-2$ & $1-2$ & $4-5$ & $4-5$ & $4-5$ & $4-5$ & $4-5$ & 5 & 4 & 4 & $4-5$ & 5 \\
\hline Binder 4 & 9.23 & $1-2$ & $1-2$ & 4 & $4-5$ & 4 & 5 & $4-5$ & 5 & 5 & $4-5$ & 5 & $4-5$ \\
\hline
\end{tabular}


Table 3. Roughness properties of screen printed cotton and polyester fabrics using printing pastes containing $5 \%$ Bercolin Red B3E, $5 \%$ of the synthesized polyurethane acrylate binders (1 - 4), as well as the commercial binder Bercolin metal CM) and thermally cured at $160^{\circ} \mathrm{C}$ for $3 \mathrm{~min}$.

\begin{tabular}{ccc}
\hline Binder Used & Cotton & Polyester \\
\hline Commercial Binder & 08.79 & 11.92 \\
Binder 1 & 08.54 & 11.56 \\
Binder 2 & 13.11 & 16.10 \\
Binder 3 & 10.64 & 15.62 \\
Binder 4 & 09.77 & 15.00 \\
\hline
\end{tabular}

Tables 4 and 5 represent the color strength and overall fastness properties of screen printed and UV cured cotton for 5 min., polyester fabrics with pigment printing pastes containing $5 \%$ polyurethane acrylate binders $(1-4)$, as well as 5\% Bercolin Red B3E pigment, as compared to that obtained upon using the commercial UV curable binder Ebecryl 2001 respectively.

The results show that, both the color strength and the fastness properties of the prints depend on the type of binder used as well as the type of the selected fabric. Binders 3 and 4 gave prints with much higher color strength results as compared to those obtained by binders 1,2 and the commercial binder.

It could be also noticed that there is a noticeable improvement in the rubbing fastness results for all the prints of all fabrics upon using all the aforementioned synthesized polyurethane acrylate binders through the use of UV curing technique as compared to those obtained by the traditional thermal curing technique. It is also clear that the UV-curing technique did not affect the printed fabric light fastness results. The washing and light fastness results of all the printed fabrics were comparable for the two techniques.

Table 6 shows the roughness properties of screen printed cotton and polyester fabrics, using printing pastes containing (5\% Bercolin Red B3E, 5\% of the synthesized polyurethane acrylate binders ( 1 - 4), as well as the com-

Table 4. The color strength and overall fastness properties of screen printed, and UV cured *cotton fabrics with pigment printing pastes containing $5 \%$ polyurethane acrylate binders (1 - 4), as well as $5 \%$ Bercolin Red B3E pigment, as compared to that upon using the commercial binder Ebecryl 2001.

\begin{tabular}{|c|c|c|c|c|c|c|c|c|c|c|c|c|c|}
\hline \multirow{3}{*}{$\begin{array}{l}\text { Binder } \\
\text { Used }\end{array}$} & \multirow{3}{*}{$\mathrm{K} / \mathrm{S}$} & \multirow{2}{*}{\multicolumn{2}{|c|}{ Rubbing }} & \multirow{2}{*}{\multicolumn{3}{|c|}{ Washing Fastness }} & \multicolumn{6}{|c|}{ Perspiration } & \multirow{3}{*}{$\begin{array}{c}\text { Light } \\
\text { Fastness }\end{array}$} \\
\hline & & & & & & & \multicolumn{3}{|c|}{ Acid } & \multicolumn{3}{|c|}{ Alkali } & \\
\hline & & Dry & Wet & Alt. & St.1 & St.2 & Alt. & St.1 & St. 2 & Alt. & St.1 & St. 2 & \\
\hline $\begin{array}{l}\text { Commercial } \\
\text { Binder }\end{array}$ & 3.61 & $2-3$ & 3 & $4-5$ & $4-5$ & $4-5$ & 5 & $4-5$ & $4-5$ & $4-5$ & $4-5$ & $4-5$ & 5 \\
\hline Binder 1 & 4.83 & $1-2$ & $1-2$ & $3-4$ & $2-3$ & 3 & 5 & $4-5$ & $4-5$ & $4-5$ & $4-5$ & $4-5$ & 5 \\
\hline Binder 2 & 8.24 & 2 & 2 & $4-5$ & $4-5$ & 4 & $4-5$ & $4-5$ & 5 & 5 & 5 & 5 & 5 \\
\hline Binder 3 & 8.12 & 4 & $3-4$ & $4-5$ & 4 & $4-5$ & 5 & $4-5$ & 5 & 5 & 5 & 5 & 5.5 \\
\hline Binder 4 & 7.76 & 4 & 4 & 4 & 3 & $3-4$ & 5 & 5 & 5 & 5 & 5 & 5 & 5.5 \\
\hline
\end{tabular}

Table 5. The color strength and overall fastness properties of screen printed, and UV cured* polyester fabrics with pigment printing pastes containing $5 \%$ polyurethane acrylate binders (1 - 4), as well as $5 \%$ Bercolin Red B3E pigment, as compared to that upon using the commercial binder Ebecryl 2001.

\begin{tabular}{|c|c|c|c|c|c|c|c|c|c|c|c|c|c|}
\hline \multirow{2}{*}{$\begin{array}{l}\text { Binder } \\
\text { Used }\end{array}$} & \multirow[b]{2}{*}{$\mathrm{K} / \mathrm{S}$} & \multirow{2}{*}{\multicolumn{2}{|c|}{ Rubbing }} & \multirow{2}{*}{\multicolumn{3}{|c|}{ Washing Fastness }} & \multicolumn{6}{|c|}{ Perspiration } & \multirow{2}{*}{$\begin{array}{c}\text { Light } \\
\text { Fastness }\end{array}$} \\
\hline & & & & & & & \multicolumn{3}{|c|}{ Acid } & \multicolumn{3}{|c|}{ Alkali } & \\
\hline $\begin{array}{l}\text { Commercial } \\
\text { Binder }\end{array}$ & 3.09 & $2-3$ & 4 & $4-5$ & 5 & $4-5$ & 5 & $4-5$ & 5 & $4-5$ & $4-5$ & $4-5$ & 5 \\
\hline Binder 2 & 3.82 & 4 & 4 & $4-5$ & 5 & 4 & $4-5$ & $4-5$ & $4-5$ & 5 & 5 & 5 & 5 \\
\hline Binder 3 & 6.43 & 3 & $3-4$ & 5 & 5 & 5 & 5 & $4-5$ & 5 & 5 & 5 & 5 & 5 \\
\hline Binder 4 & 8.92 & 3 & $3-4$ & $4-5$ & 4 & $4-5$ & 5 & $4-5$ & 5 & 5 & 5 & $4-5$ & 5 \\
\hline
\end{tabular}


Table 6. Roughness properties of screen printed cotton and polyester fabrics using printing pastes containing $5 \%$ Bercolin Red B3E, $5 \%$ of the synthesized polyurethane acrylate binders (1 - 4), as well as the commercial binder Ebecryl 2001) and UV cured for 5 min. at wave length $254 \mathrm{~nm}$.

\begin{tabular}{ccc}
\hline Binder Used & Cotton & Polyester \\
\hline Commercial binder & 11.61 & 14.88 \\
Binder 1 & 09.56 & 12.48 \\
Binder 2 & 09.01 & 12.00 \\
Binder 3 & 10.00 & 14.5 \\
Binder 4 & 12.00 & 14.25 \\
\hline
\end{tabular}

mercial binder Ebecryl 2001) and UV cured for 5 min. at wave length $254 \mathrm{~nm}$. The results show that the roughness for all these printed fabrics depends on the type of binder derivative used. Binders 1,2 gave better results than those obtained by the commercial binder and binders 3 and 4 for all the tested fabrics.

\section{Conclusions}

It could be safely concluded that, the four synthesized aqueous polyurethane acrylate binders could be successfully employed for pigment fixation on screen printed cotton, and polyester via polymerization of the binders during the thermal and UV curing processes and in general, their prints possessed better color strength values as compared to those obtained upon using the commercial binders.

The fastness properties of the prints depend on the type of binder used as well as the type of the selected textile fabric. The rubbing fastness results were low for thermally cured cotton and polyester prints, although some improvement is noticed with binders 2, 3 and 4 as compared with binder 1 and the commercial binder, their washing, perspiration and light fastness ranged from good to excellent for all.

Both concentration and type of the polyurethane binders $(1$ - 4) affect the color strength of the UV cured prints, and a binder concentration of 5\% produce prints with better color strength values, and this is the case upon using the commercial binder (Ebecryl 2001).

Higher color strength values are obtained in the case of using binders 2, 3, 4 in the UV-curable formulation as compared to the lower values obtained with the commercial binder (Ebecryl 2001), and moderate values in between, in case of using binder1. This is true irrespective of the binder concentration used.

A binder concentration of $5 \%$ is recommended, higher color strength values are obtained in case of using binders 3 and 4 as compared to those containing the commercial binder and binders 1 and 2, irrespective of the binder concentration used.

Improved rubbing fastness results for all the prints using the synthesized polyurethane acrylate binders and UV cured is noticed as compared to those obtained by the traditional thermal curing technique. UV-curing technique did not affect the printed fabric light fastness results of the printed fabrics. The washing and light fastness results are comparable for the prints produced by the two techniques. UV curing time 5 minutes is recommended.

\section{REFERENCES}

[1] W. Schwindt and G. Faulhaber, "The Development of Pigment Printing over the Last 50 Years," Review of Progress in Coloration and Related Topics, Vol.14, No. 1, 1984, pp. 166-175.

doi:10.1111/j.1478-4408.1984.tb00058.x

[2] F. L. Carlier, “Industrie Textile,” 1991, p. 68.

[3] H. Wisser, “Textil Praxis,” 1988, pp. 43-45.

[4] W. Schwindt, "Melliand Textilber,” 1990, pp. 671-693.

[5] I. Holme, Review of Progress in Coloration and Related Topics, 1992, p. 22.

[6] M. D. Teli and V. Y. Ramani, “American Dyestuff Reporter,” Vol. 81, 1992, pp. 32-37.

[7] M. D. Teli and Y. Y. Ramani, "Colorage Supplement,” Colorage, Vol. 38, No. 4, 1991, p. 23.

[8] T. Schymitzek and T. Esche, Melliand International, Vol. 2, 1997, p. 102.

[9] H. G. Smith and N. C. Gastonia, US Patent No. 6, 2001.

[10] K. P. Shah and O. H. Westlake, US Patent No. 5, 1999.

[11] W. T. Hotton and W. N. Ronald, US Patent No. 5, 1990.

[12] M. M. El-Molla, H. S. El-Sayad, M. A. El-Kashouti and R. S. El-Khawaga, "Synthesis, Characterization and Evaluation of Some New Aqueous Polyurethane Acrylate Binders,” Polish Journal of Applied Chemistry LIII, No. 4, 2009, pp. 315-322.

[13] D. B. Judd and G. Wyszenki, "Color in Business, Science and Industry,” 3rd Edition, John Wiley and Sons, New York, 1975.

[14] "Standard Methods for the Assessment of Colour Fastness of Textiles," Journal of the Society of Dyers and Colorists, Vol. 74, No. 1, 1955, pp. 22-37. doi:10.1111/j.1478-4408.1958.tb02217.x

[15] R. Eisenlohr and V. Giesrn, "Pigment Printing and Ecology,” International Dyer, Vol. 12, 1995, p. 180.

[16] S. Q. Li, H. Boyter and N. Stewart, "Ultraviolet (UV) Curing Processes for Textile Coloration," AATCC Review, Vol. 4, No. 8, 2004, pp. 44-49.

[17] Z. Wicks, F. Jones and S. Pappas, “Organic Coatings Science and Technology,” 2nd Edition, John Wiley and Sons, New York, 1999, pp. 508-515.

[18] A. V. Parys, “Coating, Eurotex,” Guimaraes, 1994, pp. 155-156. 
[19] V. R. Gowariker, N. V. Viswanathan and J. Sreedhar, Polymer Science, 1986, pp. 23-44.

[20] J. P. Fouassier, "Photoinitiation Potopolymerization and Photocuring,” Polymer International, Vol. 40, No. 4, 1996, p. 315. doi:10.1002/(SICI)1097-0126(199608)40:4<315::AID-PI 566>3.0.CO;2-T

[21] J. Loutz, S. Peeters and L. Lindekens, Journal of Coated Fabrics, Vol. 22, 1993, pp. 298-307

[22] A. Luiken, M. Marsman and R. Holweg, Journal of Coated Fabrics, Vol. 21, 1992, pp. 268-280.

[23] E. Krijnen, M. Marsman and R. Holweg, Journal of Coated Fabrics, Vol. 24, 1994, pp. 152-161.

[24] T. Kauffman and M. Mitry, Adhesives Age, Vol. 42, No. 9, 1999, pp. 27-31.

[25] W. K. Walsh, W. Oraby, A. Makati and E. Bittencourt, "Printing Symposium: Meeting the Challenge of the 80's," Proceedings of the AATCC Symposium, 1978.

[26] W. K. Walsh, et al., "High Energy Radiation for Textiles: Assessment of a New Technology: Final Report-Grant GI 43105, May 1974 to April 1977: Draft,” North Carolina State University, Raleigh, 1977.

[27] W. K. Walsh, et al., "Water-free, Low Energy Coloration Processes for Textiles: Final Report to National Science Foundation from School of Textiles, North Carolina State
University,” North Carolina State University, Raleigh, 1977.

[28] R. Schwalm, Farbe \& Lack 2000, 106, p. 58ff.

[29] Ph. Barbeau, Rad Tech Europe 99 Proc., P. 123ff.

[30] H. H. Bankowski, Rad Tech Europe 99 Proc., P. 131ff.

[31] V. Shukla, "Review of Basic Chemistry of UV-Curing Technology,” Pigment \& Resin Technology, Vol. 33, No. 5, 2004, pp. 272-279. doi:10.1108/03699420410560461

[32] J.-P. Fouassier, "Photoinitiation, Photopolymerization, and Photocuring: Fundamentals and Applications,” Hanser Gardner Publications, 1995.

[33] C. Decker, K. Zahouily, D. Decker, T. Nguyen and T. Viet, "Performance Analysis of Acylphosphine Oxides in Photoinitiated Polymerization,” Polymer, Vol. 42, No. 18, 2001 pp. 7551-7560. doi:10.1016/S0032-3861(01)00221-X

[34] K. Mehnet and H. Peter, "Printing of Cationised Cotton with Reactive Dyes,” Coloration Technology, Vol. 118, No. 6, 2002, pp. 300-306. doi:10.1111/j.1478-4408.2002.tb00114.x

[35] A. W. M. El-Naggar, et al., "Pigment Colors Printing on Cotton Fabrics by Surface Coating Induced by Electron Beam and Thermal Curing," Applied Surface Science, Vol. 241, No. 3-4, 2005, pp. 420-430. doi:10.1016/j.apsusc.2004.07.039 